\title{
Training course to become a plastic surgeon in Korea
}

\author{
Dong Ha Park
}

Director of Training \& Education Committee, Korean Society of Plastic and Reconstructive Surgeons Department of Plastic and Reconstructive Surgery, Ajou University Hospital, Suwon, Korea

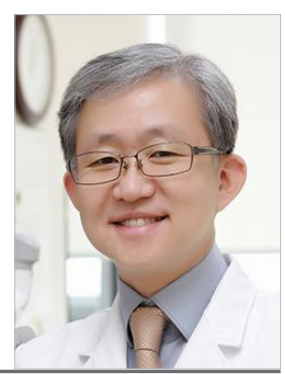

The Korean Society of Plastic and Reconstructive Surgeons (KSPRS) began administering professional training in 1964, producing the first certified specialists in 1967. After its specialized course was officially recognized in 1973, 22 specialists were trained in 1975, and 2,491 specialists have been trained to date. Throughout this period, the KSPRS has grown remarkably in both quantitative and qualitative terms, expanding its activities in the fields of trauma, chronic wounds, cosmetology, and basic research. The plastic surgery specialist course presented by the KSPRS has the goal of being "a process to become a plastic surgery specialist as an expert in reconstructive and cosmetic surgery, and to cultivate knowledge and skills as well as ethics as a responsible member of society." To this end, the KSPRS is striving to ensure proper training at each training hospital.

In order to become a plastic surgeon in Korea, after 4 years of basic training at a training hospital, the academic and medical activities required by the institute must be certified, and then trainees must pass two professional examinations. The academic competencies to become a specialist include a certain amount of papers and at least one conference presentation, as an indicator of the ability to provide evidence-based care and to successfully engage in academic communication in the specialist's chosen field, regardless of location. The purpose of training is to cultivate these competencies. In addition, clinical experience is an important component of the training process. At least 240 inpatient and 2,000 outpatient care experiences must be documented during training, as well as at least 170 cases of essential surgical procedures.

In addition, to equip trainees with expertise on rapidly changing circumstances in society and to foster a suitable ethical con- sciousness and adherence with the corresponding code of conduct, regular ethics education has been incorporated into the basic training process, both for residents and for the attending physicians who train the residents. Ethics education is now required to become an attending physician, in order to ensure that physicians are familiar with the ethics, behaviors, and norms of a wide range of social relationships, including those with their peers and neighbors, as well as the physician-patient relationship. For the above purposes, the KSPRS holds special lectures on important subjects and training sessions on special issues or topics related to ethics more than twice a year.

To date, through several reforms and improvements in the curriculum and training content, a point has been reached where new changes should be made in order to train trainees to navigate a constantly changing landscape of knowledge and skills. Academic ability among trainees will be cultivated both by recruiting a greater number of instructional specialists and by improving their capabilities. Through such initiatives, coursework will be designed for transmitting the essential knowledge and skills needed for medical treatment with using individual checklists of milestones. In addition, we will continually strive to maintain the quality of training by conducting regular surveys on training practices, in order to maintain rigorous and consistent standards. Every training hospital must complete a yearly survey on manpower, training content, facilities, and diversity of experiences. Training hospitals should provide experiences in essential surgical fields, such as head and neck surgery, hand and upper extremity surgery, breast and trunk surgery, dermatologic tumor surgery, and aesthetic surgery. Moreover, the KSPRS continues to make plans for a trainee empowerment program, 
such as developing educational milestones in the field of plastic and reconstructive surgery in Korea, expanding the content included in textbooks, and establishing an e-learning program.

The early goals articulated by the KSPRS were not fully achievable. As a field, reconstructive surgery continues to grow and become more fragmented, and concepts and practices of beauty also change over an individual's lifetime and in response to societal changes. Plastic surgery education and training in Korea should respond to these changes, not only by passively following these trends and seeking to fulfill fragmented demands, but also by actively finding ways to sympathize with patients in need and to solve their problems. We will endeavor to make continual improvements with the goals of seeking out new perspectives, communicating widely about advances in our field, and caring for our peers in order to deliver results that will be broadly recognized.

\section{NOTES}

\section{Conflict of interest}

No potential conflict of interest relevant to this article was reported.

\section{ORCID}

Dong Ha Park https://orcid.org/0000-0002-8660-7852

\section{Correspondence: Donh Ha Park}

Department of Plastic and Reconstructive Surgery, Ajou University Hospital, 206 World cup-ro, Yeongtong-gu, Suwon 16499, Korea

Tel: +82-31-219-5614, Fax: +82-31-219-5610, E-mail: growhand@hanmail.net

Received: November 8, $2019 \bullet$ Revised: December 19, 2019 • Accepted: December 23, 2019

pISSN: 2234-6163 - elSSN: 2234-6171

https://doi.org/10.5999/aps.2019.01634• Arch Plast Surg 2020;47:1-2 